\title{
Secondary Metabolites of Miconia rubiginosa
}

\author{
Juliana Rodrigues, ${ }^{1}$ Daniel Rinaldo, ${ }^{1}$ Marcelo Aparecido da Silva, ${ }^{2}$ \\ Lourdes Campaner dos Santos, and Wagner Vilegas ${ }^{1}$ \\ ${ }^{1}$ Department of Organic Chemistry, Institute of Chemistry, São Paulo State University, Araraquara, São Paulo, Brazil. \\ ${ }^{2}$ Department of Pharmacy, Federal University of Alfenas, Alfenas, Minas Gerais, Brazil.
}

\begin{abstract}
The Miconia genus is the most representative of the Melastomataceae family, and some species are commonly used in Brazilian folk medicine as anti-inflammatory agents. In this work we investigated the leaves from Miconia rubiginosa (Bonpl.) DC, using high-speed countercurrent chromatography, which yielded 11 substances (eight flavonoids, gallic acid, casuarictin, and schizandriside). Identification was achieved using nuclear magnetic resonance spectroscopy and highperformance liquid chromatography-circular dichroism-diode array detection analyses.
\end{abstract}

\section{KEY WORDS: • circular dichroism • high-speed countercurrent chromatography $\bullet$ Melastomataceae}

\section{INTRODUCTION}

$\boldsymbol{M}$ ICONIA IS A GENUS OF APPROXIMATELY 1,000 species $^{1}$ occurring in tropical America. ${ }^{2,3}$ The genus belongs to the pantropical Melastomataceae family with more than 166 genera that include about 4,300 species. ${ }^{2}$ Many of these plants are used as medicine by people living in the Cerrado area. ${ }^{4}$ Miconia infusions and extracts and compounds isolated from members of the genus have demonstrated antimicrobial, ${ }^{5}$ antibiotic, antitumoral, analgesic, and antimalarial activities. ${ }^{6,7}$

Previous phytochemical investigations of Miconia species have resulted in the isolation of triterpenes ${ }^{8,9}$ flavonoids, ${ }^{10,11}$ and quinones. ${ }^{12}$

The isolation of the compounds present in a crude extract is often performed by repeated processes based on adsorption column chromatography. In our case, we investigate mainly polar extracts containing glycosides, which can be irreversibly adsorbed on the stationary phase or even be degraded because of the catalytic activity of some solid supports. The isolated compounds are subjected to in vivo pharmacological tests, which require fast separation and milligram to gram quantities of pure compounds. Highspeed countercurrent chromatography (HSCCC) uses no solid support and has a greater maximum capacity, excellent sample recovery, efficient separation of closely related natural products, and a wider choice of solvent systems compared with conventional high-performance liquid chromatography (HPLC).

Manuscript received 16 June 2010. Revision accepted 17 September 2010.

Address correspondence to: Ms. Juliana Rodrigues, Department of Organic Chemistry, Institute of Chemistry, São Paulo State University, P.O. Box 355, Prof. Francisco Degni Street s/n, CEP 14800-900, Araraquara, SP, Brazil, E-mail: julirodr@iq.unesp.br
A prerequisite for the full understanding of molecular events involved in the biological activity of chiral molecules is the knowledge of their absolute configuration. ${ }^{13}$ The pharmacological and pharmacodynamic properties of biologically active chiral compounds are often strictly related to their stereochemistry. Enantiomers usually differ in biological activities because of their disparate interactions with enzymes and other naturally occurring chiral molecules. ${ }^{14}$ HPLC with circular dichroism (CD) detection is an excellent method for the separation and detection of these chiral compounds.

There are no reports concerning the chirality of molecules isolated from Miconia species; therefore, the scope of our analysis was to search for an efficient method to isolate in preparative scale the secondary metabolites contained in the infusion of Miconia rubiginosa (Bonpl.) DC and to establish the absolute configurations of the chiral isolates.

\section{MATERIALS AND METHODS}

\section{Reagents}

All solvents used for HSCCC were of analytical reagent grade from Merck (Darmstadt, Germany). The solvents used for HPLC were of analytical grade from J.T. Baker (Phillipsburg, NJ, USA). Water was nanopure quality, obtained from a Milli- $Q^{\circledR}$ purification system (Millipore Corp., Bedford, MA, USA).

\section{Preparation of crude sample and sample solution}

Aerial parts of $M$. rubiginosa were collected in March 2005 at Palmeiras da Serra, Pratânia, SP, Brazil, and authenticated by Dr. Luiz Fernando Rolim de Almeida from the Botany Institute, State University of São Paulo, Botucatu, 
SP, Brazil. A voucher specimen (number 25376) was deposited in the Irina Delanova Gemtchujnicov Herbarium of the Biosciences Institute, State University of São Paulo.

The dried leaves of $M$. rubiginosa $(100 \mathrm{~g})$ were separated, powdered, and extracted at $70^{\circ} \mathrm{C}$ for 10 minutes in $1 \mathrm{~L}$ of water, yielding an infusion.

Because of the presence of tannins, the infusion $(1 \mathrm{~L})$ was partitioned with ethyl acetate $(3 \times 500 \mathrm{~mL})$, with the polymeric tannins remaining in the aqueous phase and the secondary metabolites transferred to the ethyl acetate phase. The ethyl acetate fraction was evaporated at $35^{\circ} \mathrm{C}$ under reduced pressure, yielding crude extract $(1.5 \mathrm{~g}, 1.5 \%$ yield). The ethyl acetate fraction $(1.5 \mathrm{~g})$ was dissolved in a mixture consisting of $20 \mathrm{~mL}$ lower phase $+20 \mathrm{~mL}$ upper phase of the solvent system ethyl acetate/ $n$-propanol $/ \mathrm{H}_{2} \mathrm{O}$ (14:0.8:8 by volume).

\section{HSCCC}

The preparative HSCCC instrument used in this study was from P.C. Inc. (Potomac, MD, USA). It was equipped with a multiplayer with two coils of 1.68 -mm (i.d.) polytetrafluoroethylene tubing of approximately 80 and $240 \mathrm{~mL}$, respectively, with a total capacity of $320 \mathrm{~mL}$. The $\beta$ value varied from 0.5 at the internal to 0.85 at the external terminal, and the revolution radius was $10 \mathrm{~cm}(\beta=r / R$, where $r$ is the distance from the coil to the holder, and $R$ is the revolution radius or the distance between the holder axis and the central shaft). The flow rate was controlled with a Waters (Milford, MA, USA) model 4000 constant-flow pump. The sample was injected with a injection module (P.C. Inc.) with a $20-\mathrm{mL}$ sample injection loop. The coiled column was filled with the stationary phase (lower phase), then the apparatus was rotated forward at $850 \mathrm{rpm}$, and the mobile phase (upper phase) was pumped into the column in a head-to-tail direction at a flow rate of $1.0 \mathrm{~mL} /$ minute. After the mobile phase front emerged and the hydrodynamic equilibrium was established in the column, about $20 \mathrm{~mL}$ of the sample solution containing $0.75 \mathrm{~g}$ of the ethyl acetate fraction was injected through the injection module at a flow rate of $1.0 \mathrm{~mL} /$ minute. Sixty fractions of $5 \mathrm{~mL}$ each were collected with a Redifrac automated fraction collector (Pharmacia, Uppsala, Sweden), in approximately 5 hours. After thin-layer chromatography (TLC) analyses, fractions with similar retardation factor $\left(R_{\mathrm{F}}\right)$ were combined. The procedure was repeated with the remaining 0.75 -g ethyl acetate fraction.

\section{Preparation of the two-phase solvent system}

The solvent system, composed of ethyl acetate/ $n$-propanol/ $\mathrm{H}_{2} \mathrm{O}$ (14:0.8:8 by volume), was thoroughly equilibrated overnight in a separator funnel at room temperature, and the two phases were separated shortly before use.

\section{TLC and HPLC analyses}

Aliquots of the ethyl acetate and the collected fractions were analyzed on glass-backed silica gel TLC $(20 \times 20 \mathrm{~cm}$, Aldrich, Milwaukee, WI, USA), with the mobile phase being $\mathrm{CHCl}_{3} /$ methanol/ $n$-propanol $/ \mathrm{H}_{2} \mathrm{O}$ (5:6:1:4 by volume). The TLC plates were evaluated under ultraviolet (UV) light $(254 \mathrm{~nm})$ and derivatized with anisaldehyde $/ \mathrm{H}_{2} \mathrm{SO}_{4}$ solution. ${ }^{15}$ The infusion and the isolated metabolites were additionally analyzed using a Jasco $^{\circledR}$ (Tokyo, Japan) HPLC system equipped with a PU-2089 Plus pump, a MD-2010 Plus photodiode array detector, a CD-2095 Plus CD detector, an AS-2055 Plus autosampler, and a $\mathrm{C}_{18}$ column $(250 \times 4.60 \mathrm{~mm}$ i.d.; particle size, $5 \mu \mathrm{m}$; Luna, Phenomenex, Torrance, CA, USA), and a Phenomenex security guard $(4.0 \times 2.0 \mathrm{~mm}$ i.d.). EZChrom Elite ${ }^{\mathrm{TM}}$ version 3.1.7 software (Agilent Technologies, Palo Alto, CA, USA) was used for control of the analytical system, data collection, and processing. The mobile phase was acetonitrile + trifluoroacetic acid $(0.05 \%)$ (eluent A) and $\mathrm{H}_{2} \mathrm{O}+0.05 \%$ trifluoroacetic acid (eluent B), with a linear gradient elution of A:B 13:87 (vol/vol) to A:B 23:77 (vol/vol) in 40 minutes and then to $100 \% \mathrm{~A}$ in 45 minutes at a flow rate of $1.0 \mathrm{~mL} /$ minute, and the effluent was monitored at $254 \mathrm{~nm}$. The infusion was applied to a solid-phase extraction cartridge $\left(20 \mathrm{mg}\right.$, Sep Pak $\mathrm{C}_{18}$, Waters), which was preconditioned with $10 \mathrm{~mL}$ of HPLC-grade methanol and $10 \mathrm{~mL}$ of water $(18 \mathrm{~m} \Omega \cdot \mathrm{cm})$. A suitable amount of sample (to load $20 \mathrm{mg}$ of infusion/g of solid phase) was loaded onto the $\mathrm{C}_{18}$ cartridge, eluted with $5 \mathrm{~mL}$ of $\mathrm{H}_{2} \mathrm{O}$ /methanol (8:2, fraction 1), $5 \mathrm{~mL}$ of $\mathrm{H}_{2} \mathrm{O} /$ methanol $(1: 1$, fraction 2$)$, and $5 \mathrm{~mL}$ of methanol (100\%, fraction 3), and dried using a stream of $\mathrm{N}_{2}$. The residues of the three fractions were redissolved in $2 \mathrm{~mL}$ of $\mathrm{H}_{2} \mathrm{O} /$ methanol $(8: 2$, vol/vol) and filtered through a membrane polytetrafluoroethylene filter (pore size, $0.45 \mu \mathrm{m}$; Millex, Millipore), and $20 \mu \mathrm{L}$ of this filtrate was subjected to HPLC-UV-diode array detection (DAD) analysis.

The chiral study was performed with a polysaccharidederived chiral stationary phase column (Chiralcel OD-RH ${ }^{\circledR}$; particle size, $5 \mu \mathrm{m} ; 250 \times 4.6 \mathrm{~mm})$ protected by a Chiralcel OD-RH guard column (particle size, $5 \mu \mathrm{m} ; 10 \times 4.0 \mathrm{~mm}$ ) (Daicel Chemical Industries, Tokyo). The CD spectra were scanned between 220 and $420 \mathrm{~nm}$ for the resolved enantiomers using the online $\mathrm{CD}$ detector. The spectra were average computed over three instrumental scans, and the intensities are presented in terms of ellipticity values.

\section{Structural identification of the compounds}

Nuclear magnetic resonance (NMR) spectra (one- and two-dimensional) were obtained in dimethyl sulfoxide (DMSO) $-d_{6}$ using a Varian (Palo Alto) INOVA 500 spectrometer operating at $500 \mathrm{MHz}$ for ${ }^{1} \mathrm{H}$ and $125 \mathrm{MHz}$ for ${ }^{13} \mathrm{C}$.

\section{Spectroscopic data}

Compound 9 was a white amorphous powder of composition $\mathrm{C}_{15} \mathrm{H}_{14} \mathrm{O}_{6}$ with $\lambda_{\max }$ (in methanol) of 214 and $279 \mathrm{~nm}$. By ${ }^{1} \mathrm{H}-\mathrm{NMR}$ (DMSO- $\left.d_{6}\right): 2.50(d d, J=4.5 ; 16.0 \mathrm{~Hz}, 1 \mathrm{H}, \mathrm{H}-$ $\left.4^{\mathrm{b}}\right), 2.67\left(d d, J=4.5 ; 16.0 \mathrm{~Hz}, 1 \mathrm{H}, \mathrm{H}-4^{\mathrm{a}}\right), 4.02(s, 1 \mathrm{H}, \mathrm{H}-3)$, $4.74(s, 1 \mathrm{H}, \mathrm{H}-2), 5.73(d, J=2 \mathrm{~Hz}, 1 \mathrm{H}, \mathrm{H}-6), 5.89(d$, $J=2 \mathrm{~Hz}, 1 \mathrm{H}, \mathrm{H}-8), 6.66\left(m, 1 \mathrm{H}, \mathrm{H}-5^{\prime}\right), 6.67\left(m, 1 \mathrm{H}, \mathrm{H}-6^{\prime}\right)$, $6.89\left(d, J=1.5 \mathrm{~Hz}, 1 \mathrm{H}, \mathrm{H}-2^{\prime}\right)$.

Compound $\mathbf{1 0}$ was a colorless amorphous powder of composition $\mathrm{C}_{41} \mathrm{H}_{28} \mathrm{O}_{26}$ with $\lambda_{\max }$ (in methanol) of 223 and 


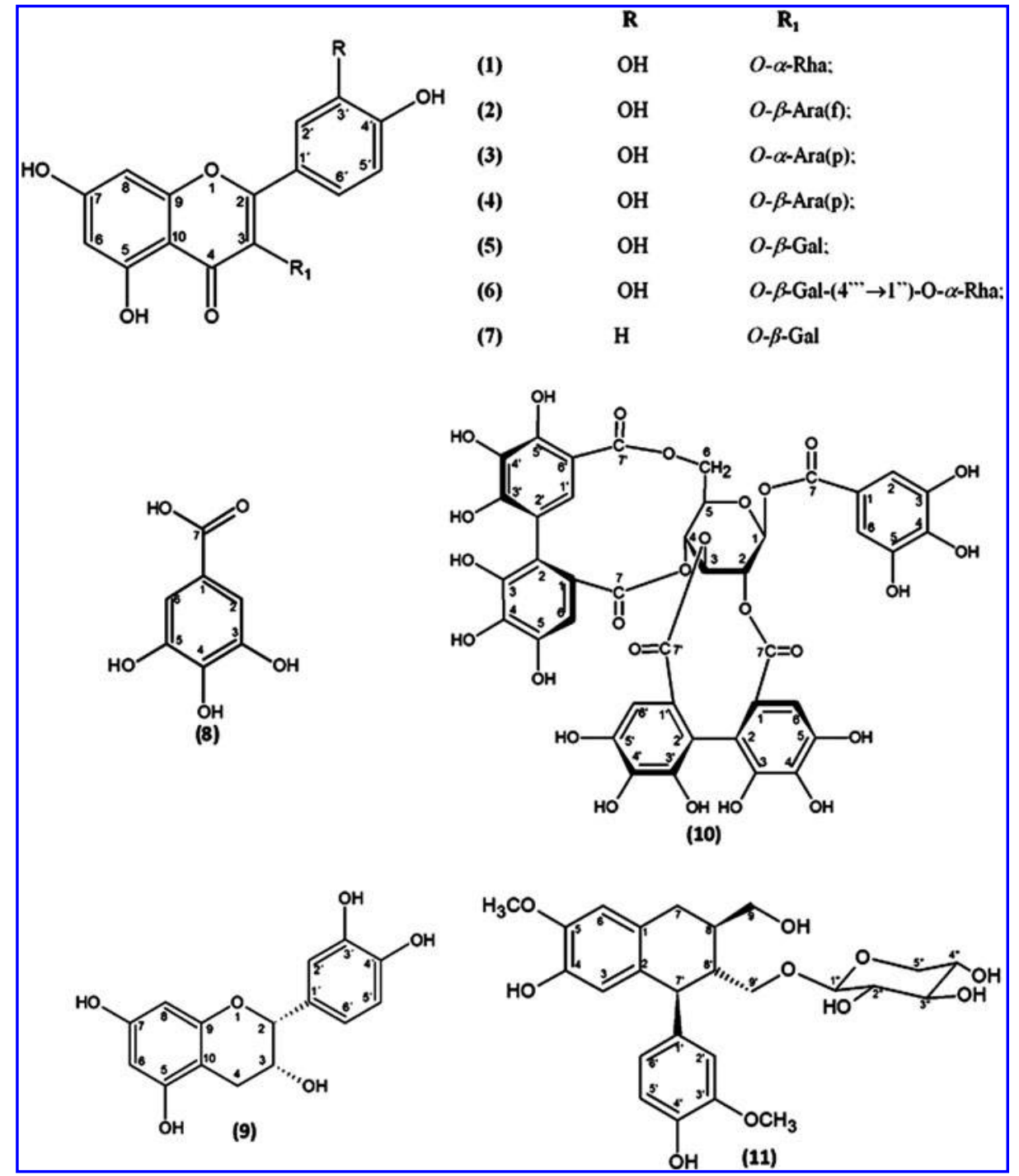

$280 \mathrm{~nm}$. By ${ }^{1} \mathrm{H}-\mathrm{NMR}$ (DMSO- $\left.d_{6}\right): 3.84(d, J=13 \mathrm{~Hz}, 1 \mathrm{H}, \mathrm{H}-$ $\left.6^{\mathrm{a}}\right), 4.58(d d, J=7.0 ; 9.0 \mathrm{~Hz}, 1 \mathrm{H}, \mathrm{H}-5), 4.99(t, J=10 \mathrm{~Hz}$, $1 \mathrm{H}, \mathrm{H}-4), 5.00(t, J=10 \mathrm{~Hz}, 1 \mathrm{H}, \mathrm{H}-2), 5.12(d d, J=6.5$; $\left.13.0 \mathrm{~Hz}, 1 \mathrm{H}, \mathrm{H}-6^{\mathrm{b}}\right), 5.49(t, J=9.0 \mathrm{~Hz}, 1 \mathrm{H}, \mathrm{H}-3), 6.27(d$, $J=8.5 \mathrm{~Hz}, 1 \mathrm{H}, \mathrm{H}-1$ anom), 6.17, 6.25, 6.38, $6.44(s$, each $1 \mathrm{H}, \mathrm{HHDP}-\mathrm{H}), 7.02(s, 2 \mathrm{H}$, galloyl $\mathrm{H})$.

Compound 11 was colorless needles of composition $\mathrm{C}_{25} \mathrm{H}_{32} \mathrm{O}_{10}$ with $\lambda_{\max }$ (in methanol) of 207 and $284 \mathrm{~nm}$. By ${ }^{1} \mathrm{H}-\mathrm{NMR}$ (DMSO- $\left.d_{6}\right): 1.72\left(t, J=10.5 \mathrm{~Hz}, 1 \mathrm{H}, \mathrm{H}-8^{\prime}\right), 1.89$ $(t t, J=3.5 ; 10.5 \mathrm{~Hz}, 1 \mathrm{H}, \mathrm{H}-8), 2.73(d, J=6.5 \mathrm{~Hz}, 2 \mathrm{H}, \mathrm{H}-7)$, $2.98\left(m, 1 \mathrm{H}, \mathrm{H}-5^{\prime \prime}\right), 2.99\left(m, 1 \mathrm{H}, \mathrm{H}-9^{\prime}\right), 2.99\left(m, 1 \mathrm{H}, \mathrm{H}-2^{\prime \prime}\right)$, $3.09\left(d t, J=9.0 \mathrm{~Hz}, 1 \mathrm{H}, \mathrm{H}-3^{\prime \prime}\right), 3.27\left(m, 1 \mathrm{H}, \mathrm{H}-4^{\prime \prime}\right), 3.47(m$, $1 \mathrm{H}, \mathrm{H}-9), 3.58(d d, J=4.0 ; 10.0 \mathrm{~Hz}, 1 \mathrm{H}, \mathrm{H}-9), 3.66(d d$, $\left.J=5.5 ; 11.5 \mathrm{~Hz}, 1 \mathrm{H}, \mathrm{H}-5^{\prime \prime}\right), 3.70\left(s, 1 \mathrm{H}, \mathrm{OCH}_{3}\right), 3.72(s, 1 \mathrm{H}$, $\left.\mathrm{OCH}_{3}\right), 3.86\left(d d, J=2.5 ; 9.5 \mathrm{~Hz}, 1 \mathrm{H}, \mathrm{H}-9^{\prime}\right), 3.93(d$, $\left.J=7.5 \mathrm{~Hz}, 1 \mathrm{H}, \mathrm{H}-1^{\prime \prime}\right), 4.03\left(d, J=10.5 \mathrm{~Hz}, 1 \mathrm{H}, \mathrm{H}-7^{\prime}\right), 6.10$ $(s, 1 \mathrm{H}, \mathrm{H}-3), 6.49\left(d d, J=1.5 ; 8.0 \mathrm{~Hz}, 1 \mathrm{H}, \mathrm{H}-6^{\prime}\right), 6.62(s, 1 \mathrm{H}$, $\mathrm{H}-6), 6.70\left(d, J=8.0 \mathrm{~Hz}, 1 \mathrm{H}, \mathrm{H}-5^{\prime}\right), 6.80(d, J=1.5 \mathrm{~Hz}, 1 \mathrm{H}$, $\left.\mathrm{H}-2^{\prime}\right)$.
FIG. 1. Secondary metabolites of $M$. rubiginosa.

\section{RESULTS}

A series of experiments was performed to determine a suitable two-phase solvent system for HSCCC. Small amounts of the ethyl acetate fraction were dissolved in test tubes containing each of the following solvent systems: ethyl acetate $/ n$-propanol $/ \mathrm{H}_{2} \mathrm{O}$ (14:0.8:8 by volume), ethyl acetate $/ n$-butanol $/ \mathrm{H}_{2} \mathrm{O}$ (14:0.4:8 by volume), and hexane/ ethyl acetate/methanol $/ \mathrm{H}_{2} \mathrm{O}$ (1:1:1:1 by volume). The test tubes were shaken, and the system was allowed to equilibrate between the two phases. An aliquot of each phase was spotted on a TLC plate $\left(\mathrm{CHCl}_{3} /\right.$ methanol $/ n$-propanol $/ \mathrm{H}_{2} \mathrm{O}$ [5:6:1:4 by volume]), visualized under UV light $(254 \mathrm{~nm})$, and developed with anisaldehyde $/ \mathrm{H}_{2} \mathrm{SO}_{4}$ solution. The twophase solvent system was selected according to the partition coefficients $(K)$ of the target components. The $K$ values were determined by TLC analysis according to Conway. ${ }^{16}$ The best result was obtained with the mixture of ethyl acetate/ $n$-propanol $/ \mathrm{H}_{2} \mathrm{O}$ (14:0.8:8 by volume), with the substances 
almost equally distributed between the two phases. The relatively high proportion of ethyl acetate in the solvent mixture and the $R_{\mathrm{F}}$ values of the compounds indicate the medium polarity of the metabolites of M. rubiginosa. Thus the upper phase was chosen as the mobile phase, and the lower phase was used as the stationary phase for the HSCCC separation of the ethyl acetate fraction of the infusion of $M$. rubiginosa. This choice has the additional advantage that the upper phase consists largely of the volatile ethyl acetate, readily eliminated by evaporation.

Under the conditions described, the retention of the stationary phase in the HSCCC was $87 \%$. This method led to the isolation of the compounds in approximately 3.5 hours, and the whole process was completed in 5 hours. Spectroscopic analyses allowed identification of 11 main compounds, determined by comparison with literature data: quercetin-3-O $\alpha$-rhamnopyranoside (1), ${ }^{17}$ quercetin-3-O- $\beta$-arabinofuranoside (2), ${ }^{18}$ quercetin-3- $O$ - $\alpha$-arabinopyranoside (3), ${ }^{19}$ quercetin-3- $O$ $\beta$-arabinopyranoside (4), ${ }^{19}$ quercetin-3- $O$ - $\beta$-galactopyranoside (5), ${ }^{18}$ quercetin-3- $O-\alpha$-rhamnopyranosil- $(1 \rightarrow 4)-O-\beta$-galactopyranoside (6) ${ }^{19}$ kaempferol-3-O- $\beta$-galactopyranoside (7), ${ }^{19}$ gallic acid (8), ${ }^{19,20}(-)$-epicatechin $(\mathbf{9}),{ }^{4}$ casuarictin $(\mathbf{1 0}),{ }^{21}$ and schizandriside (11) ${ }^{22}$ (Fig. 1).

The identity and purity of the isolated substances were verified by HPLC-CD-DAD analyses using authentic samples from a collection of our laboratory. All substances were obtained with purity $>95 \%$.

Figure 2 shows the HPLC chromatographic analysis of fraction 2 of the infusion of $M$. rubiginosa aerial parts. The peaks were identified by co-injection with purified metabolites.

The compounds isolated-(-)-epicatechin (9), casuarictin (10), and schizandriside (11) - were analyzed by HPLCCD-DAD using a chiral column (OD-RH) with metha-

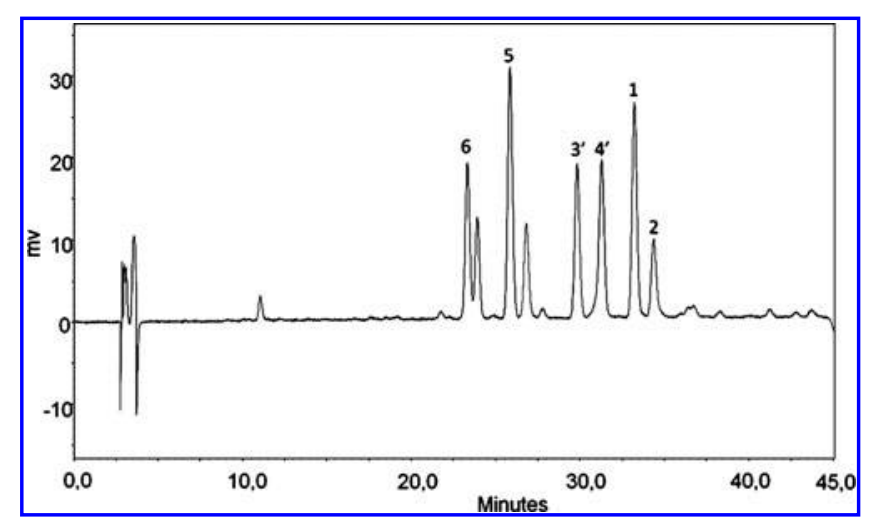

FIG. 2. Chromatogram of the infusion of $M$. rubiginosa by highperformance liquid chromatography analysis: quercetin-3-O$\alpha$-rhamnopyranoside (1), quercetin-3-O- $\beta$-arabinofuranoside (2), quercetin-3-O- $\alpha$-arabinopyranoside (3), quercetin-3-O- $\beta$-arabinopyranoside (4), quercetin-3-O- $\beta$-galactopyranoside (5), and quercetin3-O- $\alpha$-rhamnopyranosil-( $1 \rightarrow 4)-O$ - $\beta$-galactopyranoside $(\mathbf{6})$. Eluent A, acetonitrile $+0.05 \%$ trifluoroacetic acid; eluent $\mathrm{B}, \mathrm{H}_{2} \mathrm{O}+0.05 \%$ trifluoroacetic acid. Method: 13-23\% B in A (40 minutes); $23-100 \%$ B in A (45 minutes); flow rate, $1.0 \mathrm{~mL} /$ minute; injection volume, $20 \mu \mathrm{L}$; Phenomenex Luna $\mathrm{C}_{18}$ column; detection at $254 \mathrm{~nm}$. *Might be inverted. nol $/ \mathrm{H}_{2} \mathrm{O}$ (4:6, vol/vol) as eluent. The chromatograms showed only one peak, indicating that all the substances were present in enantiomerically pure forms in this species. The CD spectra were recorded for the establishment of the absolute configuration of these substances (Fig. 3).

\section{DISCUSSION}

Several classes of natural products have been isolated by HSCCC, including flavonoids. ${ }^{23,24}$ Our group reported the isolation of naphthopyranone glycosides from Paepalanthus microphyllus (Family Eriocaulaceae), ${ }^{25}$ quercetin glycosides and the biflavonoid amentoflavone from Byrsonima crassa (Family Malpighiaceae), ${ }^{26}$ the flavones 6-methoxyluteolin-7-O- $\beta$-D-allopyranoside and 6-methoxyapigenin-7$O$ - $\beta$-D-allopyranoside from Eriocaulon ligulatum (Family Eriocaulaceae), ${ }^{27}$ and quercetin-3- $O-\alpha$-L-rhamnopyranoside and myricetin-3-O- $\alpha$-L-rhamnopyranoside from Davilla elliptica (Family Dilleniaceae). ${ }^{28}$

The separation mechanism of HSCCC is based mainly on the differential solubility of the compound between the two immiscible phases, one flowing along the other, allowing the fast and efficient isolation of several compounds without decomposition. HSCCC, being a support-free liquid-liquid partition chromatographic technique, eliminates irreversible adsorption of the sample onto the solid support, and

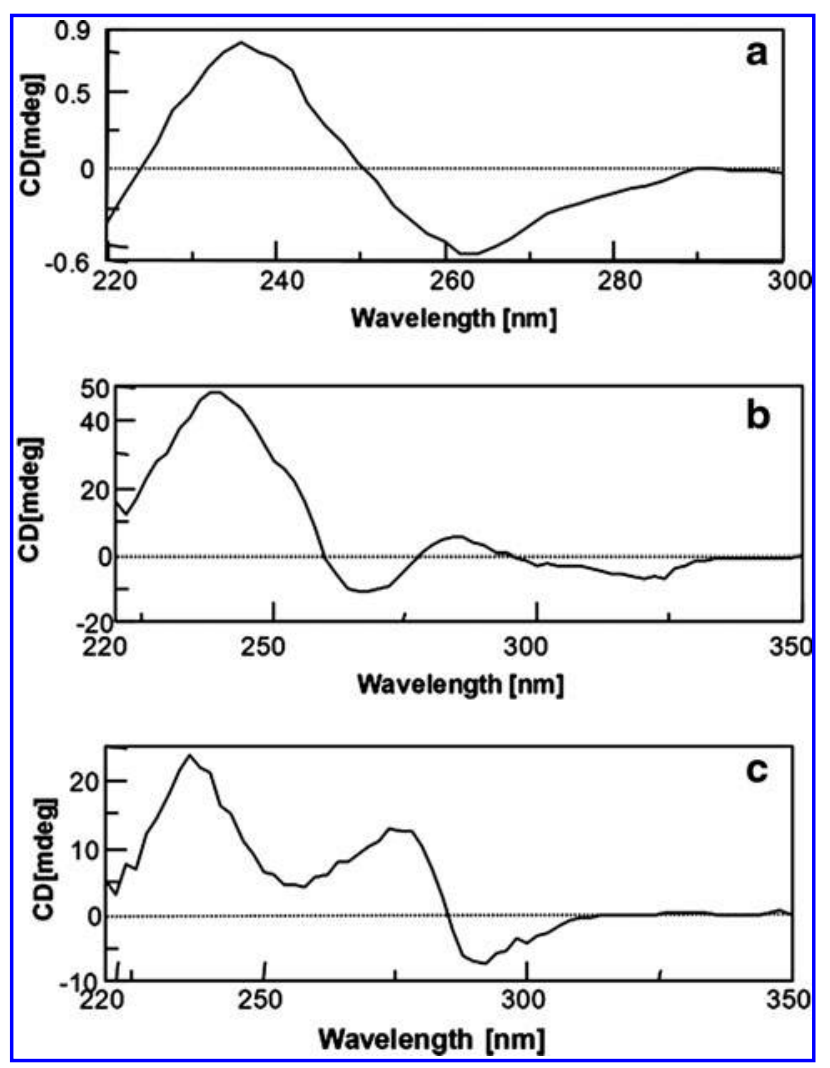

FIG. 3. Circular dichroism (CD) spectra of (a) (-)-epicatechin (9), (b) casuarictin (10), and (c) schizandriside (11). mdeg, ellipticity value. 
therefore this method has been widely used for the preparative separation of natural products. ${ }^{29,30}$

Despite the similar polarities of the compounds, they were well separated, with the separation of the quercetin and kaempferol glycosides dependent on the total number of the hydroxyl groups. Our results showed that the conditions used provided an efficient method for the separation of the metabolites from $M$. rubiginosa.

Catechins are an important class of secondary metabolites. They show strong antioxidant activity and have various health-related activities, such as anticarcinogenic, antiallergic, anti-atherogenic, antibacterial, and antiviral activities. ${ }^{31}$ These biological activities are significantly influenced by stereochemical differences, thus justifying the determination of the chirality of these metabolites.

Catechin derivatives have two stereocenters, resulting in four diastereomers, These substances have two aromatic chromophores, namely, the benzene A- and B-rings, with the absorption bands of these chromophores found at approximately 280 and $240 \mathrm{~nm} .{ }^{32}$ The positive Cotton effect in the $240 \mathrm{~nm}$ region $\left(L_{\mathrm{a}}\right.$ transition, chromophore B) and the negative Cotton effect in the $280 \mathrm{~nm}\left(L_{\mathrm{b}}\right.$ transition, chromophore $\mathrm{A})$ regions indicate $(2 R, 3 R)$ absolute configuration, elucidating 9 as (-)-epicatechin (Fig. 3). This is the first report of the isolation of catechins from plants of the Melastomataceae family.

Casuarictin (10) is an example of a hydrolyzable tannin. Plants with high tannin content are used in traditional medicine to treat various diseases such as diarrhea, hypertension, rheumatism, bleeding, wounds, burns, stomach problems, kidney problems, and inflammatory processes. ${ }^{33}$ Several studies have shown the presence of hydrolyzable tannins in species of the Melastomataceae family. ${ }^{34,35}$

Casuarictin (10) (which is a monomeric $\beta$-glucosyl ellagitannin) presents atropisomerism due to the restricted rotation of the biphenyl bond of the hexahydroxydiphenoyl (HHDP) group. Casuarictin (10) displayed three Cotton effects, around 235, 265, and $285 \mathrm{~nm}$. These Cotton effects are associated with the biphenyl conjugation bands in the UV spectra. The Cotton effect at $235 \mathrm{~nm}$ is diagnostic for the absolute configuration of the HHDP group [positive for the $(S)$ - and negative for the $(R)$-configuration]..$^{21}$

The CD spectra of $\mathbf{1 0}$ exhibited a positive Cotton effect at $235 \mathrm{~nm}$, thus indicating the $(S)$-configuration for HHDP groups.

Schizandriside (11) is an aryltetralin-type glycosylated lignan. This compound exhibited moderate antioxidant activity $^{22}$ and moderate antibacterial activity against Escherichia coli, Staphylococcus aureus, Micrococcus luteus, and Bacillus cereus using the paper disk method. ${ }^{36}$

The absolute structure of $\mathbf{1 1}$ was established based on CD spectroscopic evidence. Klyne et al. ${ }^{37}$ proposed a CD empirical rule that states that all $7^{\prime} \alpha$-aryl derivatives in $7^{\prime}$ aryltetralin-type lignans give a positive Cotton effect at $280-290 \mathrm{~nm}$, whereas all $7^{\prime} \beta$-aryl groups display a negative Cotton effect. The CD spectrum of $\mathbf{1 1}$ afforded a negatively signed maximum at $284 \mathrm{~nm}$, indicating $7^{\prime} \beta\left(7^{\prime} S\right)$ configuration. The large ${ }^{3} J_{7^{\prime}, 8^{\prime}}$ and ${ }^{3} J_{8,8^{\prime}}$ coupling constants
$(J=11.0 \mathrm{~Hz})$ established the absolute configuration as $\left(7^{\prime} S, 8^{\prime} R, 8 R\right)$.

The results of our studies clearly demonstrate the potential of HSCCC for the preparative isolation of secondary metabolites from the leaves of $M$. rubiginosa. In particular, preparative HSCCC, with its speedy separation and minimum solvent consumption, offers an efficient method for the separation and purification of natural products.

The compounds $\mathbf{1}, \mathbf{8}$, and $\mathbf{9}$ were previously isolated from the Miconia cabucu species. ${ }^{10}$ The others were isolated for the first time from Miconia species. There has been no report about the optical study of metabolites isolated from species of the Melastomataceae family. The HPLC-CD-DAD analyses showed that all the chiral substances isolated from M. rubiginosa were presented in enantiomerically pure forms. Their absolute configurations were established as (-)-epicatechin, casuarictin [(S)-HHDP], and $\left(7 S, 8 R, 8^{\prime} R\right)$ schizandriside, respectively.

\section{ACKNOWLEDGMENTS}

We thank the Fundação de Amparo à Pesquisa do Estado de São Paulo for funding from the Biota-Fapesp Program and the Conselho Nacional de Desenvolvimento Científico Tecnológico for a grant to W.V. We also thank CAPES for a fellowship to J.R. and M.A.S.

\section{AUTHOR DISCLOSURE STATEMENT}

No competing financial interests exist.

\section{REFERENCES}

1. Martins AB, Semir J, Goldenberg R, Martins E: O gênero $M i$ conia Ruiz \& Pav. no Estado de São Paulo. Acta Bot Bras 1996;10:267-316.

2. Renner SS: Phylogeny and classification of the Melastomataceae and Memecylaceae. Nord J Bot 1993;13:519-540.

3. Judd WS, Skean JD Jr: Phylogeny and classification of the Melastomataceae and Memecylaceae. Bull Florida Mus Nat Hist 1991;36:25-84.

4. Almeida SCX, Lemos TLG, Silveira ER, Pessoa ODL: [Volatile and non-volatile chemical constituents of Cochlospermun vitifolium (Willdenow) Sprengel]. Quim Nova 2005;28:57-60.

5. Rodrigues J, Michelin DC, Rinaldo D, Zocolo GJ, Dos Santos LC, Vilegas W, Salgado HRN: Antimicrobial activity of Miconia species (Melastomataceae). J Med Food 2008;11:120-126.

6. Hasrat JA, De Backer JP, Valquelin G, Vlietinck AJ: Medicinal plants in Suriname: screening of plants extracts for receptobinding activity. Phytomedicine 1997;4:56-65.

7. Cunha WR, Martins C, Ferreira DS, Crotti AEM, Lopes NP, Albuquerque $\mathrm{S}$ : In vitro trypanocidal activity of triterpenes from Miconia species. Planta Med 2003;69:468-470.

8. Chan WR, Sheppard V, Medford KA, Tinto WF: Triterpenes from Miconia stenostachya. J Nat Prod 1992;55:963-966.

9. Macari PAT, Emerenciano VP, Ferreira ZMGS: [Identification of triterpenes from Miconia albicans through analysis by microcomputer]. Quim Nova 1990;13:260-262.

10. Rodrigues J, Rinaldo D, Dos Santos LC, Vilegas W: An unusual $\mathrm{C}_{6}-\mathrm{C}_{6^{\prime \prime}}$ linked flavonoid of Miconia cabucu (Melastomataceae). Phytochemistry 2007;68:1781-1784. 
11. Li XC, Jacob MR, Pasco DS, ElSohly HN, Nimrod AC, Walker LA, Clark AM: Phenolic compounds from Miconia myriantha

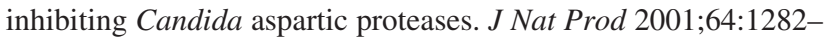
1285.

12. Bernays E, Lupi A, Bettolo RM, Mastrofrancesco C, Tagliatesta P: Antifeedant nature of the quinone primin and its quinol miconidin from Miconia spp. Experientia 1984;40:1010-1011.

13. Cirilli R, Ferretti R, La Torre F, Borioni A, Fares V, Camalli M, Faggi C, Rotili D, Mai A: Chiral HPLC separation and absolute configuration of novel S-DABO derivatives. Chirality 2009;21: 604-612.

14. Lin K, Xu C, Zhou S, Liu W, Gan J: Enantiomeric separation of imidazolinone herbicides using chiral high-performance liquid chromatography. Chirality 2007;19:171-178.

15. Wagner HM, Bladt S, Zgainki EM: Plant Drug Analysis. Springer, Berlin, 1984.

16. Conway WD: Countercurrent Chromatography-Apparatus, Theory and Applications. VCH, New York, 1990.

17. Bilia AR, Ciampi L, Mendez J, Morelli I: Phytochemical investigations of Licania genus. Flavonoids from Licania pyrifolia. Pharm Acta Helv 1996;71:199-204.

18. Ossipov V, Nurmi K, Loponen J, Prokopiev N, Haukioja E, Pihlaja K: HPLC isolation and identification of flavonoids from white birch Betula pubescens leaves. Biochem Syst Ecol 1995;23: 213-222.

19. Agrawal PK: Carbon-13 NMR of Flavonoids. Elsevier, Amsterdam, 1989.

20. Harborne JB: The Flavonoids: Advances in Research Since 1986. Chapman and Hall, London, 1996.

21. Okuda T, Yoshida T, Hatano T, Koga T, Toh N, Kuriyama K: Circular dichroism of hydrolysable tannins-I. Ellagitannins and gallotannins. Tetrahedron Lett 1982;23:3937-3940.

22. Sadhu SK, Khatun A, Phattanawasina P, Ohtsuki T, Ishibashi M: Lignan glycosides and flavonoids from Saraca asoca with antioxidant activity. J Nat Med 2007;61:480-482.

23. Zhou X, Peng J, Fan G, Wu Y: Isolation and purification of flavonoid glycosides from Trollius ledebouri using high-speed counter-current chromatography by stepwise increasing the flow-rate of the mobile phase. J Chromatogr A 2005;1092:216221.

24. Si W, Gong J, Tsao R, Kalab M, Yang R, Yin Y: Bioassayguided purification and identification of antimicrobial compo-

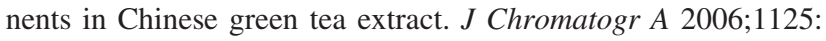
204-210.
25. Dos Santos LC, Piacente S, De Ricardis F, Eletto AM, Pizza C, Vilegas W: Xanthones and flavonoids from Leiothrix curvifolia and Leiothrix flavescens. Phytochemistry 2001;56:853-856.

26. Sannomiya M, Rodrigues CM, Coelho RG, Dos Santos LC, Hiruma-Lima CA, Brito ARMS, Vilegas W: Application of preparative high-speed counter-current chromatography for the separation of flavonoids from the leaves of Byrsonima crassa Niedenzu (IK). $J$ Chromatogr A 2004;1035:47-51.

27. Dos Santos LC, Silva MA, Rodrigues CM, Rodrigues J, Rinaldo D, Sannomiya M, Vilegas W: [Fast preparative separation of flavones from capitula of Eriocaulon ligulatum (Vell.) L.B. Smith]. Rev Cienc Farm Basica Apl 2005;26:101-103.

28. Rinaldo D, Silva MA, Rodrigues CM, Calvo TM, Sannomiya M, Dos Santos LC, Vilegas W, Kushima H, Hiruma-Lima CA, Brito ARMS: [Preparative separation of flavonoids from the medicinal plant Davilla elliptica St. Hill. by high-speed counter-current chromatography]. Quim Nova 2006;29:947-949.

29. Conway WD, Petroski RJ: Modern Countercurrent Chromatography. American Chemical Society, Washington, DC, 1995.

30. Han X, Zhang T, Wei Y, Cao X, Ito Y: Separation of salidroside from Rhodiola crenulata by high-speed counter-current chromatography. J Chromatogr A 2002;971:237-241.

31. Kodama S, Yamamoto A, Matsunaga A, Yanai H: Direct enantioseparation of catechin and epicatechin in tea drinks by 6-O$\alpha$-D-glucosyl- $\beta$-cyclodextrin-modified micellar electrokinetic chromatography. Electrophoresis 2004;25:2892-2898.

32. Slade D, Ferreira D, Marais JPJ: Circular dichroism, a powerful tool for the assessment of absolute configuration of flavonoids. Phytochemistry 2005;66:2177-2215.

33. Simões CMO, Schemkel EP, Gosmann G, Mello JCP, Mentz LA, Petrovick PR: Farmacognosia: da Planta ao Medicament. Ed. UFRGS, Porto Alegre/UFSC, Florianópolis, Brazil, 2001.

34. Yoshida T, Ito H, Hipólito IJ: Pentameric ellagitannin oligomers in melastomataceous plants-chemotaxonomic significance. Phytochemistry 2005;66:1972-1983.

35. Isaza JH, Ito H, Yoshida T: A flavonol glycoside-lignan ester and accompanying acylated glucosides from Monochaetum multiflorum. Phytochemistry 2001;58:321-327.

36. Dong L, Ni W, Dong J, Li J, Chen C, Liu H: A new neolignan glycoside from the leaves of Acer truncatem. Molecules 2006;11:1009-1014.

37. Klyne W, Stevenson R, Swan RJ: Optical rotatory dispersion. 28. Absolute configuration of otobain and derivatives. $\underline{\text { Chem Soc C }}$ 1966;9:893-896. 
This article has been cited by:

1. Erika M. de O. Ribeiro, Luciano S. Lima, Jorge M. David, Ademir E. do Vale, Lucia M.X. Lopes, Juceni P. David. 2013. A new tropane alkaloid and other constituents of Erythroxylum rimosum (Erythroxylaceae). Phytochemistry Letters 6:2, $232-235$. [CrossRef] 